\title{
O FUNCIONÁRIO PÚBLICO E SUA IMAGEM SOCIAL
}

\author{
MÁRA RUBIA TRIGO ${ }^{1}$
}

\author{
Programa de Pós-graduação em Linguística Aplicada \\ Universidade de Taubaté - UNITAU \\ R. Visconde do Rio Branco, 210 - 12.020-040 - Taubaté - SP - Brasil \\ trigomararubia@gmail.com
}

\begin{abstract}
Resumo. O objetivo dessa pesquisa é investigar qual o teor dos enunciados envolvendo o funcionário público nas esferas artística, política e civil, selecionados nos portais nacionais da Internet, e discutir a relação existente entre valoração e ideologia e sua materialização nesses enunciados. A hipótese é de que eles foram ideologicamente construídos, contribuindo para fortalecer a imagem pejorativa do funcionário público. Essa pesquisa é fundamentada no estudo bibliográfico da teoria bakhtiniana e aborda os conceitos de valoração, ideologia e enunciado. Sua conclusão confirmou que os enunciados investigados foram ideologicamente construídos, a partir do juízo de valor da sociedade, contribuindo para o fortalecimento da imagem pejorativa do funcionário público, pelas interações sociais.
\end{abstract}

Palavras-chave: Enunciado; Ideologia; Valoração.

\begin{abstract}
The objective of this research is to investigate the content of the statements involving the public official in the artistic, political and civil spheres, selected in the national Internet portals, and to discuss the existing relationship between valuation and ideology, and their materialization in these statements. The hypothesis is that they were ideologically constructed, contributing to strengthen the pejorative image of the public official. This research is based on the bibliographic study of Bakhtinian theory, and addresses the concepts of valuation, ideology and utterance. Its conclusion confirmed that the investigated statements were ideologically constructed, based on the value judgment of society, contributing to the strengthening of the pejorative image of the public official, through social interactions.
\end{abstract}

Keywords: Statement; Ideology, Valuation.

\section{INTRODUÇÃO}

Do ponto de vista conceitual, funcionários públicos podem ser definidos como aqueles que ocupam cargos ou empregos na administração pública direta ou indireta, em

\footnotetext{
${ }^{1}$ Mestranda do Programa de Pós-graduação em Linguística Aplicada da Universidade de Taubaté UNITAU.
} 
quaisquer dos poderes da União, dos Estados, do Distrito Federal e dos Municípios, com a qual mantêm vínculo de trabalho profissional. Atuam em diversas áreas da sociedade, cuja administração e funcionamento são de responsabilidade do estado brasileiro como, por exemplo: saúde, segurança e educação.

De acordo com o Instituto de Pesquisa Econômica Aplicada - IPEA [s.d.], nas últimas três décadas o número de funcionários públicos teve um aumento superior a cem por cento, constituindo uma população de 11,4 milhões de pessoas distribuídas entre as esferas federal, estadual e municipal. A forma como esses funcionários são remunerados por seu trabalho variam de acordo com a esfera na qual atuam, podendo se observar que em razão da política salarial adotada por cada um dos poderes que a constitui, o executivo, o legislativo e o judiciário, a existência de disparidade nos valores remuneratórios.

Do ponto de vista social, a figura do funcionário público foi instituída pela Constituição Federal de 1891, porém desde o Brasil colônia já se podia notar sua presença nas relações de trabalho com o estado brasileiro, geridas por modelos de administração que contribuíram, historicamente, para a construção social da sua imagem na sociedade brasileira. Tal imagem, foi construída a partir de inúmeros enunciados que circularam e ainda circulam em diversas esferas da atividade humana, reproduzindo, reconstruindo, organizando e significando, por meio dos signos, que constituem o processo de interação social, o conceito de funcionário público.

Esse fato nos mostra a presença da consciência ideológica a respeito do funcionário público. Na perspectiva de Bakhtin (2006), a consciência ideológica é produto da interação semiótica do grupo social onde os enunciados circulam por meio dos signos no curso das relações sociais. Ao emergirem e se materializarem no processo de interação social, esses signos ganham status de fenômeno ideológico, mostrando que a ideologia se constrói a partir de um movimento dialético que se realiza nesse processo de interação. Assim temos que os enunciados a respeito do funcionário público, carregados de signos que dão a essa classe de trabalhadores uma significação, quando pronunciados por diversos atores sociais, em um processo de interação social e verbal, vão ganhando status de fenômeno ideológico e construindo o conceito ideológico de funcionário público.

Esse enunciado é o que podemos chamar de enunciado concreto concebido, na perspectiva bakhtiniana, como o resultado do processo da interação social entre os participantes da enunciação em uma situação de uso real da língua, sendo uma unidade da comunicação verbal. Segundo Bakhtin (1997), o enunciado concreto envolve a alternância dos sujeitos falantes promovendo um diálogo real entre eles, definido como uma forma clássica de comunicação verbal.

Com fundamento nesses conceitos bakhtinianos, podemos afirmar que os enunciados produzidos, a respeito do funcionário público, nas diferentes esferas da atividade humana e sob diferentes gêneros discursivos, podem ser definidos como enunciados concretos, visto que constituem uma cadeia de comunicação verbal, que envolve participantes da enunciação em uso real da língua.

No entanto esses enunciados a respeito do funcionário público são produzidos de forma genérica. A ideologia inerente àqueles que os produzem não os permitem 
considerar para sua construção as especificidades inerentes a cada carreira pública, ignorando-se as diversidades existentes entre elas, que revelam o contraste na administração de pessoal da administração pública. Dessa forma, observa-se uma diversidade de construção de enunciados fundamentados em um conceito generalizado de funcionário público, que é reproduzido de forma a rotular, indistintamente, essa classe de trabalhadores.

Em razão desse fato, essa pesquisa estabeleceu como objetivo geral investigar qual o teor de alguns enunciados envolvendo a figura do funcionário público brasileiro, proferidos por atores sociais da esfera artística, política e civil. Como objetivo específico, estabelece-se levantar e investigar a relação existente entre valoração e ideologia e como esses conceitos são materializados nos enunciados selecionados, contribuindo para a construção e o fortalecimento da imagem social do funcionário público.

Os enunciados selecionados para análise se constituem na canção Maria Candelária, de autoria de Armando Cavalcanti e Klecius Caldas, na década de 50, nos recortes da propaganda governamental a favor da reforma da previdência divulgada na rede social do governo federal, Twitter, em 2017 durante o governo do presidente Michel Temer, nos recortes dos enunciados referentes aos pronunciamentos proferidos pelo ministro da economia Paulo Guedes, em palestra realizada na Fundação Getúlio Vargas, em 2020, e no recorte do artigo de opinião publicado pelo jornalista Walmaro Paz, em 2020, no site de notícias denominado Brasil de Fato, em homenagem ao funcionário público. Todos os enunciados citados acima foram selecionados nos portais nacionais da Internet por meio da amostragem por acessibilidade, e todos eles são direcionados à figura do funcionário público. Seus detalhamentos encontram-se registrados nos quadros 1, 2, 3 e 4 adiante.

A hipótese levantada nessa pesquisa é a de que os enunciados aqui investigados são ideologicamente construídos, e que na sua maioria, contribuem para fortalecer a imagem pejorativa do funcionário público.

Essa é uma pesquisa de investigação qualitativa, de natureza interpretativa e do tipo documental, fundamentada no estudo bibliográfico da teoria bakhtiniana, abordando os conceitos de valoração, ideologia e enunciado.

Esses enunciados, de natureza diversa, segundo Godoy (1995), são construídos a partir de um determinado ponto vista e revelam as concepções, as ideias e as opiniões daqueles que o construíram, se constituindo em uma fonte de informações que pode ser analisada para a compreensão de alguns fenômenos sociais.

A importância de se fazer tal pesquisa reside no fato de que a mesma significa uma oportunidade de provocar uma reflexão a respeito de como os enunciados que circulam na sociedade se referem ao funcionário público, fato que pode contribuir para o deslocamento do diálogo construído a seu respeito no meio social, criando novos sentidos e significações a essa classe de trabalhadores. 


\section{REFERENCIAL TEÓRICO}

\section{ENUNCIAÇÃO, VALORAÇÃO, IDEOLOGIA E GÊNERO DISCURSIVO SOB A PERSPECTIVA BAKHTINIANA}

Não há como se falar em enunciação sem se falar em interação verbal, uma vez que esses dois conceitos estão intrinsicamente ligados. Não há interação verbal sem enunciação, e não há enunciação sem interação verbal. Isso fica evidente na afirmação de Bakhtin (2006, p. 114), "a enunciação é o produto da interação de dois indivíduos socialmente organizados e, mesmo que não haja um interlocutor real, este pode ser substituído pelo representante médio do grupo social ao qual pertence o locutor".

Assim, a enunciação é considerada como o ato de enunciar-se, de dirigir-se a alguém, a um interlocutor, em um espaço social onde ocorre a interação entre ambos. Segundo Bakhtin (2006), a enunciação é sempre determinada pelas condições sociais que cercam o momento da interação entre o locutor e o interlocutor, ou seja; pelo contexto social, cultural e histórico em que a enunciação ocorre, ou pelas condições sociais mais imediatas em que se dá a interação, e que determina, por exemplo, o que deve ser dito e a quem vai ser dito. Para Bakhtin (2006, p. 115-116), "a situação social mais imediata e o meio social mais amplo determinam completamente e, por assim dizer, a partir do seu próprio interior, a estrutura da enunciação". Esses fatores, somados a outros, como por exemplo a ideologia do grupo social envolvido na enunciação, são os fatores que de fato reorganizam o discurso e são indispensáveis à sua compreensão, conferindo à enunciação o seu caráter social.

Esse caráter social da enunciação fica explícito na afirmação de Bakhtin (1997, p. 321), de que "(...) o enunciado, desde o início, elabora-se em função da eventual reaçãoresposta, a qual é o objetivo preciso de sua elaboração", de onde concluiu que o outro, a quem o locutor dirige a sua fala, tem um papel muito importante no processo de comunicação, considerando-se que espera-se dele uma resposta, uma compreensão responsiva ativa. Esse outro, nada mais é que o horizonte social do locutor:

\footnotetext{
Enquanto falo, sempre levo em conta o fundo aperceptivo sobre o qual minha fala será recebida pelo destinatário: o grau de informação que ele tem da situação, seus conhecimentos especializados na área de determinada comunicação cultural, suas opiniões e suas conviç̧ões, seus preconceitos (de meu ponto de vista), suas simpatias e antipatias, etc.; pois é isso que condicionará sua compreensão responsiva de meu enunciado. (BAKHTIN, 1997, p. 322).
}

Esse enunciado concreto que ocorre entre o locutor e o outro, o interlocutor, é marcado pela alternância dos sujeitos falantes, ou seja, ora o locutor é o interlocutor e ora o interlocutor é o locutor, dando assim espaço para a atitude responsiva ativa.

No entanto, quando o locutor fala, o objeto de seu discurso, da sua fala, não é inédito, segundo Bakhtin (1997, p. 320), "o objeto, por assim dizer, já foi falado, controvertido, esclarecido e julgado de diversas maneiras, é o lugar onde se cruzam, se encontram e se separam diferentes pontos de vista, visões do mundo, tendências", 
portanto, o enunciado não é inédito e nem o seu locutor é o primeiro a se enunciar sobre o seu objeto.

De acordo com Bakhtin (1997, p. 316), “o enunciado está repleto dos ecos e lembranças de outros enunciados, aos quais está vinculado no interior de uma esfera da comunicação verbal". Sendo assim, o enunciado é uma resposta a enunciados anteriores aos quais se refuta, se confirma, completa, ou neles se baseiam ou os supõe conhecidos dentro da esfera da comunicação. Isso porque, dentro da esfera de comunicação verbal, o enunciado ocupa uma posição bem definida a respeito de uma determinada questão, razão pela qual ele é sempre considerado e avaliado no momento da produção de novos enunciados ou de enunciados resposta. Essa é a questão que faz com que um enunciado alheio, do outro, seja inserido no contexto do nosso próprio enunciado, seja através de palavras ou de orações completas, podendo-se nesse "empréstimo", conservar a alteridade de tais elementos na expressão do nosso discurso ou modificá-los (dar a eles um sentido de ironia, indignação, admiração etc.), ou ainda parafraseá-los.

Segundo Bakhtin (2006), por ser de natureza social, a enunciação é ideológica e para explicar essa afirmação, aborda a relação existente entre o signo e a situação social e a ideologia, apontando para o fato de que a ideologia está intrinsicamente ligada ao signo e à consciência:

Tudo que é ideológico possui um significado e remete a algo situado fora de si mesmo. Em outros termos, tudo que é ideológico é um signo. Sem signos não existe ideologia. (BAKHTIN, 2006, p. 29).

A consciência adquire forma e existência nos signos criados por um grupo organizado no curso de suas relações sociais. Os signos são o alimento da consciência individual, a matéria de seu desenvolvimento, e ela reflete sua lógica e suas leis. A lógica da consciência é a lógica da comunicação ideológica, da interação semiótica de um grupo social. (BAKHTIN, 2006, p. 34).

De acordo com a citação acima, a consciência somente existe por meio dos signos que emergem e se materializam no processo das interações sociais, passando então a se constituir do conteúdo ideológico e semiótico que circulam no meio social em que essas interações ocorrem. Esse conteúdo ideológico e semiótico aparece claramente na linguagem, em que a palavra ganha o status de fenômeno ideológico.

Para Bakhtin (2006, p. 40), "as palavras são tecidas a partir de uma multidão de fios ideológicos e servem de trama a todas as relações sociais em todos os domínios". As palavras carregam em si tanto o seu valor semiótico como o ideológico, esse último ancorado na ciência, na arte, na moral e no direito, na medida em que refletem e refratam a realidade social do grupo em que se dá a enunciação. Sendo assim, conforme Bakhtin (2006, p. 40), a palavra é "(...) o indicador mais sensível de todas as transformações sociais $(\ldots) "$.

Ao passar por todo esse processo de formação, segundo Bakhtin (2006, p. 120), "(...) a consciência torna-se uma força real, capaz mesmo de exercer em retorno uma ação sobre as bases econômicas da vida social", o que lhe permite afirmar que é o nosso mundo interior que se adapta às nossas possibilidades de expressão, aos seus caminhos e 
orientações possíveis e não o contrário. A essa expressão da consciência, dá o nome de ideologia do cotidiano.

A ideologia do cotidiano constitui o domínio da palavra interior e exterior desordenada e não fixada num sistema, que acompanha cada um dos nossos atos ou gestos e cada um dos nossos estados de consciência. (BAKHTIN, 2006, p. 121).

Essa ideologia do cotidiano está dividida em dois níveis, o inferior e o superior. $\mathrm{O}$ inferior que tem suas raízes nos encontros fortuitos da vida cotidiana, nos acontecimentos do dia a dia, que normalmente são de caráter relativamente instáveis, não adquirindo força e durabilidade no plano social. Já o nível superior é constituído das interações sociais que envolvem uma relação efetiva com os sistemas ideológicos instituídos denominados de ideologia oficial, como por exemplo a ciência, a religião, a moral etc. Nesse nível superior, a ideologia do cotidiano é capaz de fazer repercutir as mudanças da infraestrutura socioeconômica e colaborar para a construção de novas forças sociais e ideológicas. Essas novas forças sociais e ideológicas acabam por efetuar revisões parciais ou totais dos sistemas ideológicos e invadir a ideologia oficial constituída, renovando-as, assim como renovando-se a si mesma.

Observa-se, então, que ambas as ideologias, cotidiana e oficial, estão intimamente ligadas entre si e vão se construindo e reconstruindo-se nas interações que ocorrem entre os grupos sociais, por meio das enunciações, da linguagem:

Os sistemas ideológicos constituídos da moral social, da ciência, da arte e da religião cristalizam-se a partir da ideologia do cotidiano, exercem por sua vez sobre esta, em retorno, uma forte influência e dão assim normalmente o tom a essa ideologia. (BAKHTIN, 2006, p. 121).

Assim, pode-se dizer que ideologia é produto das interações sociais que ocorrem por meio do movimento dialético e que refletem e refratam a realidade vivida pelos grupos sociais, o que permite a construção de novas significações de mundo e de realidades por meio da linguagem, onde a palavra encontra grande destaque.

Para Bakhtin (1997), ao escolhermos as palavras de nossos enunciados nesses processos de interação social, partimos sempre das intenções que fundamentam aquilo que queremos enunciar, por isso o nosso enunciado é sempre expressivo e cada uma das palavras que escolhemos pronunciar irradia essa nossa expressividade. Bakhtin (1997) afirma que "a emoção, o juízo de valor, a expressão são coisas alheias à palavra dentro da língua, e só nascem graças ao processo de sua utilização ativa no enunciado concreto", assim, a expressividade da palavra vem unicamente do enunciado e não do seu significado linguístico isolado.

Para a construção de nossos enunciados, considera-se que nem sempre escolhemos as palavras no sistema de línguas, muitas vezes as escolhemos e as tiramos de outros enunciados pertencentes a gêneros discursivos que se aproximam do nosso próprio gênero e que conferem à nossa palavra uma determinada expressão. De acordo com Bakhtin (1997), quando essas palavras que compõem o nosso enunciado foram tiradas de enunciados individuais dos outros, elas podem manter no nosso enunciado o 
seu tom valorativo, sua expressividade e ressonância originais, que assimilamos, ou modificamos.

No gênero, a palavra comporta certa expressão típica. Os gêneros correspondem a circunstâncias e a temas típicos da comunicação verbal e, por conseguinte, a certos pontos de contato típicos entre as significações da palavra e a realidade concreta. (BAKHTIN, 1997, p. 313).

Assim, conclui-se que toda palavra utilizada no enunciado concreto carrega em si não apenas o seu significado linguístico, mas principalmente um valor, um tom apreciativo que é transmitido por meio de uma entoação expressiva, que na maioria das vezes é determinada pela situação imediata em que se dá a sua enunciação, a realidade concreta.

Para Bakhtin (1997, p. 314), "na medida em que uso essa palavra numa determinada situação, com uma intenção discursiva, ela já se impregnou de minha expressividade", de forma que, sendo assim, segundo ele, a palavra expressa o juízo de valor daquele que a enuncia.

Além disso, os enunciados que circulam na época e no meio social em que se vive, as tradições, as ideologias, também servem de inspiração aos enunciados, colaborando para a construção do seu tom valorativo, o seu juízo de valor.

Assim, verifica-se que a valoração tem relação com o tempo e o espaço e a ideologia, que são marcas que mobilizam o sentido das enunciações nos movimentos de interação social e expressam um posicionamento do locutor em relação ao seu enunciado.

Esses enunciados, marcados pelo tom valorativo de seus enunciadores, são constituídos de três elementos, definidos por Bakhtin (1997) como conteúdo temático, estilo e construção composicional.

Fundamentada no pensamento de Bakhtin, Berti-Santos (2012) apresenta a definição desses três elementos constitutivos do enunciado. O primeiro elemento, conteúdo temático, é definido como sendo uma unidade de significação que constitui cada enunciado, estando sempre voltado às especificidades da esfera onde o enunciado é produzido. $\mathrm{O}$ estilo se refere às formas típicas de enunciação, escolhas e seleção dos recursos léxicos, fraseológicos e gramaticais da língua. Já a forma composicional, é definida por Berti-Santos (2012, p. 180), como "plano de expressão, da estrutura, da sequência organizacional, integrante e constituinte das especificidades sintáticas de cada gênero discursivo". É o que define, portanto, sua macro estrutura.

$\mathrm{Na}$ construção dos enunciados, esses três elementos se fundem refletindo as circunstâncias e as especificidades da esfera de onde foram produzidos, instituindo-se assim um tipo de enunciado relativamente estável, definido por Bakhtin (1997) como gêneros de discurso.

De acordo com Machado (2005), Bakhtin distingue dois tipos de gêneros discursivos, os gêneros primários, que se referem à comunicação cotidiana, e os gêneros secundários, que se referem a uma comunicação mais complexa, organizada em sistemas 
específicos, como a ciência, a arte e a política. Músicas, gêneros jornalísticos e discursos publicitários, como os abordados nessa pesquisa, são exemplos de gêneros secundários.

Segundo Machado (2005), para Bakhtin essa classificação dos gêneros não os impede de se relacionarem, se influenciarem e se completarem, considerando que as esferas em que ambos se instalam, se relacionam constantemente, mostrando que o gênero tem um caráter enunciativo, cuja formação depende do contexto comunicativo e da cultura, sendo concebidos com finalidade comunicativa e expressiva.

\section{A CONTRIBUIÇÃO DA ADMINISTRAÇÃO PÚBLICA PARA A CONSTRUÇÃO DA IMAGEM ESTIGMATIZADA DO FUNCIONÁRIO PÚBLICO}

Desde o tempo do Brasil colônia é possível observar a presença do funcionário público nas relações de trabalho com o estado brasileiro. Presença essa que foi se adaptando aos diversos modelos de administração aos quais o Brasil foi submetido no decorrer da sua história.

De acordo com Chiavenato (2009), partindo-se de uma perspectiva histórica, observa-se que a administração pública no Brasil adotou três modelos básicos de administração: o patrimonialista, o burocrático e o gerencial.

Segundo Chiavenato (2009), no modelo patrimonialista, tinha-se uma administração corrupta, em que os cargos públicos ocupados no âmbito da administração da colônia eram considerados prebendas, sendo doados a pessoas escolhidas pela corte, e tinham como característica uma alta remuneração em troca de pouco trabalho. Essa se tornou uma marca do serviço público que, ainda nessa sociedade contemporânea, reflete na imagem do funcionário público, contribuindo para que o mesmo receba o estereótipo de privilegiado por, supostamente, receber muito e trabalhar pouco. Já o modelo burocrático, segundo Chiavenato (2009), com o objetivo de combater a corrupção e o nepotismo, era constituído de controles rígidos e hierarquizados que garantiam o controle e o poder soberano do Estado. No entanto, a ânsia pelo controle, que era a razão de ser do funcionário, fazia com que o estado se voltasse para si mesmo e negligenciasse os serviços prestados à sociedade.

Nesse modelo de administração, o Estado não conseguiu implantar uma política de recursos humanos que atendesse as suas reais necessidades, e nem combater de forma efetiva o patrimonialismo que continuou mantendo sua força política e, consequentemente, o clientelismo na administração pública. Esse modelo burocrático, em razão da sua rigidez, segundo Chiavenato (2009), passou por diversas reformas que acabaram por flexibilizar a política de pessoal do Estado, que optou por contratar, por meio das estatais, funcionários para compor o escalão da administração direta, deixando de investir no desenvolvimento do funcionário público, que passou a ser visto como um peso para o Estado brasileiro. Esse fato, segundo Chiavenato (2009), enfraqueceu o modelo burocrático, dando origem ao modelo gerencial, orientado pelos valores da eficiência e qualidade dos serviços públicos prestados ao cidadão, porém um modelo que não chegou a romper definitivamente com a administração burocrática. 
Hoje observa-se que tais características inerentes a esses modelos de administração, como o engessamento oriundo da administração burocrática, a falta de investimentos em treinamento e desenvolvimento de carreiras e a própria característica de prebendas inerente aos cargos públicos no Brasil colônia refletem na construção de diversos enunciados a respeito do funcionário público, especialmente quando se trata de por em discussão a sua atuação como um agente público a serviço da sociedade. Tal fato expõe o funcionário público a uma diversidade de discursos, nem sempre favoráveis à sua atuação, como os que veremos a seguir.

\section{OBJETOS DE ANÁLISE E CONSIDERAÇÕES A RESPEITO DE SUAS ENUNCIAÇÕES}

A seguir identificamos os objetos de análise dessa pesquisa, pronunciados em diversas esferas da sociedade brasileira, selecionados por meio da amostragem por acessibilidade ou por conveniência, aplicável em estudos exploratórios ou qualitativos, em que, segundo Gil (2008, p. 94), "o pesquisador seleciona os elementos a que tem acesso, admitindo que estes possam, de alguma forma, representar o universo". Assim, consideramos que os enunciados identificados abaixo representam, em sua maioria, a definição de funcionário público predominante na sociedade brasileira.

\section{MARCHINHA MARIA CANDELÁRIA}

Tabela 1. Discurso 1 - Maria Candelária (Marchinha de Carnaval)

\begin{tabular}{|c|c|}
\hline \multicolumn{2}{|c|}{ Discurso de: Armando Cavalcanti e Klecius Caldas } \\
\hline Veiculado: Site eletrônico letras de & e música para ouvir \\
\hline Ano: 1952 & Acesso: $08 / 06 / 2020$ \\
\hline $\begin{array}{l}\text { Integra todo o discurso: } \\
\text { Maria Candelária } \\
\text { É alta funcionária } \\
\text { Saltou de paraquedas } \\
\text { Caiu na letra "O", oh, oh, oh, oh } \\
\text { Começa ao meio-dia } \\
\text { Coitada da Maria } \\
\text { Trabalha, trabalha } \\
\text { Trabalha de fazer dó oh, oh, oh, oh } \\
\text { Maria Candelária } \\
\text { É alta funcionária } \\
\text { Saltou de paraquedas } \\
\text { Caiu na letra "O", oh, oh, oh, oh }\end{array}$ & $\begin{array}{l}\text { Começa ao meio-dia } \\
\text { Coitada da Maria } \\
\text { Trabalha, trabalha } \\
\text { Trabalha de fazer dó oh, oh, oh, oh } \\
\text { A uma vai ao dentista } \\
\text { Às duas vai ao café } \\
\text { Às três vai à modista } \\
\text { Às quatro assina o ponto } \\
\text { E dá no pé } \\
\text { Que grande vigarista que ela é. }\end{array}$ \\
\hline
\end{tabular}

A marchinha Maria Candelária é uma composição da década de 50 e se constitui em um protesto elaborado, de forma descontraída e bem humorada, à classe do funcionário público, representado na canção pela personagem Maria Candelária.

Com fundamento na teoria de Bakhtin (1997), a respeito dos gêneros discursivos, podemos dizer que a canção está inserida na esfera artística-musical da atividade humana, 
podendo ser considerada um gênero discursivo secundário, mais especificamente um gênero musical, composto de letra e música.

Enquanto gênero musical, essa marchinha possui estabilidade temática e reproduz em sua letra os enunciados populares, de senso comum, que definem e constituem a consciência ideológica da sociedade da época, em relação ao funcionário público. Por essa razão, esses enunciados não podem ser compreendidos fora do contexto histórico em que foram produzidos. Para essa compreensão registramos que essa canção retrata uma prática, recorrente na época da sua composição, para a admissão de funcionários públicos, identificada como apadrinhamento. Uma prática possível em decorrência das especificações e abrangências do concurso público, identificadas na Carta Constitucional de 1934, que deixava aberta a possibilidade de acesso ao serviço público por outros meios que não o concurso público. Essa prática está representada no enunciado dessa marchinha, já nos primeiros versos, "Maria Candelária é alta funcionária saltou de paraquedas", em que os compositores fazem uma insinuação a respeito da forma como Maria Candelária conseguiu seu emprego na administração pública, sugerindo que ele não foi fruto do mérito de suas qualificações profissionais, mas sim de apadrinhamento e influência políticos.

Nos versos seguintes, observa-se uma referência às condições que atribuem à Maria Candelária o adjetivo de vigarista: uma funcionária que através de suas atitudes descompromissadas com o trabalho vai ludibriando a administração pública, desrespeitando seus horários de entrada e saída e sendo displicente com suas atividades laborais para tratar de seus assuntos particulares, fatos que ironicamente são tratados, pelos compositores, como excesso de trabalho. Esses enunciados apontam a ideia de improdutividade, ineficiência e descompromisso com o trabalho, como uma síntese dos aspectos semânticos definidores do funcionário público, aspectos que constituem os discursos que circulam a seu respeito na sociedade da época.

Assim, o autor traz para a esfera artística musical esse discurso da vida cotidiana que é reelaborado e reproduzido em um outro contexto: um contexto carnavalesco, uma festa popular que alcança toda classe social. Nessa esfera, por meio de seus elementos composicionais, como a melodia e o ritmo que dão voz a ela, a marchinha é inserida em todas as esferas da atividade humana. Essa inserção promove uma amplificação dos seus enunciados, que ao serem aceitos e reproduzidos no meio social, passam a expressar o sentimento coletivo da sociedade em relação ao funcionário público, instituindo-se, assim, uma crítica social a essa classe de trabalhadores e contribuindo para fortalecer sua imagem pejorativa. Isso nos mostra que a canção é um gênero discursivo que ultrapassa as barreiras da sociedade, sejam elas culturais ou econômicas, influenciando a maneira de falar e até mesmo de pensar e agir de seus ouvintes. Os posicionamentos ideológicos apontados nas enunciações dessa canção contribuem para esvaziar o sentido do trabalho na administração pública e para promover a discriminação da mulher na sociedade, ao insinuar que ela é dedicada às futilidades do dia a dia e não está preparada para a vida profissional. 


\section{RECORTES DA CAMPANHA A FAVOR DA REFORMA DA PREVIDÊNCIA}

\section{Tabela 2. Discurso 2 - Recorte da propaganda governamental a favor da reforma da previdência}

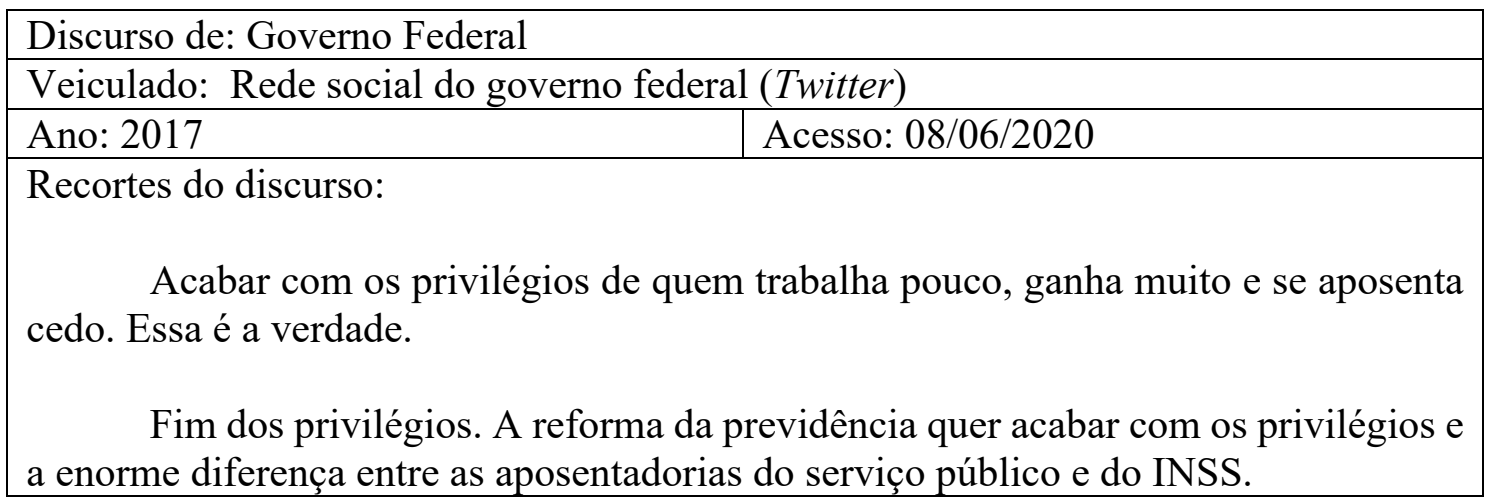

Os recortes de que trata essa análise constituem a propaganda governamental, na forma de vídeo, que trata da intenção do governo federal de alterar o sistema previdenciário brasileiro, por meio da sua proposta de reforma da previdência. Essa reforma abrangeria alterações na forma de conceder e remunerar os benefícios previdenciários no âmbito do funcionalismo público e da iniciativa privada. A necessidade de realização dessa reforma, segundo o governo federal, encontrava amparo na escassez de recursos financeiros que viabilizassem a continuidade do pagamento desses benefícios, a médio prazo, a todos os brasileiros, com base nas regras previdenciárias então vigentes. Essa era uma reforma estrutural, que sendo impopular na sua origem, necessitava de apoio, tanto político quanto social, para ser aprovada.

Assim, com o suposto intuito de angariar apoio da sociedade à aprovação dessa reforma, o governo federal divulgou oficialmente em sua rede social, twitter, no ano de 2017, sua propaganda oficial em defesa da reforma, em que o funcionário público figurava como o protagonista de uma situação previdenciária privilegiada em detrimento dos demais trabalhadores brasileiros, fato que pode ser notado nos enunciados destacados na tabela 2.

Observa-se que o enunciado ganha muito, remete a uma excelente condição financeira e consequentemente social, que não corresponde à realidade da maioria da sociedade brasileira, que pode ser classificada como classe assalariada, de baixa renda, que vive dos recursos provenientes de seu trabalho no proletariado e que observa na expressão ganha muito uma questão de injustiça social. Podemos observar também que ganhar muito é um enunciado que se opõe ao enunciado trabalhar pouco, apontando para o que se supõe ser uma contradição existente no serviço público: funcionários que pouco trabalham em troca de um alto salário. No entanto, o enunciado ganha muito mantém encoberta a realidade do funcionário público admitido após as mudanças legislativas ocorridas entre 1998 e 2012, que aproximaram o valor pago a título de aposentadoria em ambos os seguimentos, público e privado, eliminando a possibilidade de aposentadoria integral aos novos funcionários públicos. Já o enunciado se aposenta cedo, faz uma 
referência à idade cronológica do funcionário público, insinuando que se aposentar cedo seja um benefício inerente à sua categoria. Ao destacar essa questão, o enunciado se silencia quanto à instituição da exigência de idade mínima no funcionalismo público, em 1998, como condição para a concessão da aposentadoria voluntária. Tal situação retardou a concessão dessas aposentadorias em até sete anos, considerando que, se antes da exigência da idade mínima um cidadão, ao entrar no serviço público aos dezoitos anos de idade se aposentaria aos cinquenta e três anos de idade, ao completar trinco e cinco anos de trabalho, tempo mínimo exigido para se aposentador voluntariamente, após a exigência da idade mínima, esse mesmo cidadão somente se aposentaria aos sessenta anos de idade, somando quarenta e dois anos de trabalho, sete anos além do tempo mínimo de trabalho exigido para aposentadorias voluntárias. Tal fato mostrava que os funcionários públicos estavam permanecendo por mais tempo em atividade, contrariando o enunciado da propaganda que os caracterizava como aqueles que se aposentavam cedo.

A forma com que esses enunciados aqui citados foram construídos, destacando os supostos privilégios do funcionário público e a necessidade de eliminá-los, sugere que as mudanças propostas pelo projeto da reforma da previdência alcançariam apenas os funcionários públicos, excluindo-se os trabalhadores da iniciativa privada, considerando que, de acordo com os enunciados, os funcionários da iniciativa privada não eram detentores de privilégios. Fato que mantém oculta a abrangência da reforma proposta.

Destaca-se que os enunciados aqui citados foram produzidos em uma esfera governamental, onde há a predominância de enunciações ideológicas típicas das relações dialógicas estabelecidas nessa esfera. Além disso, pode-se notar também, que os enunciados dessa propaganda estabeleceram um diálogo com enunciados anteriores a respeito do funcionário público, predominantemente pejorativos, pronunciados em outras esferas da atividade humana que integram a comunicação da vida cotidiana. Essa relação dialógica estabelecida contribuiu para fortalecer a imagem pejorativa do funcionário público e aumentar a rejeição social a essa classe de trabalhadores. O fortalecimento dessa imagem depreciativa, aliada à suposta condição de privilegiado do funcionário público, instiga o sentimento de injustiça social naqueles que não sendo privilegiados, passam a ver a reforma da previdência como uma forma de lhe fazer justiça. Com isso, pode-se observar que a construção dos enunciados dessa propaganda foi estrategicamente pensada para atender aos interesses ideológicos do governo federal, origem dos enunciados. Dessa forma, articulou sentidos que pudessem conduzir a sociedade a uma atitude responsiva de seu interesse: o apoio incondicional à reforma da previdência e o fortalecimento da imagem pejorativa do funcionário público.

\section{RECORTE DA FALA DO MINISTRO PAULO GUEDES EM PALESTRA REALIZADA NA FUNDAÇÃO GETÚLIO VARGAS EM DEFESA DA REFORMA ADMINISTRATIVA}

Tabela 3: Discurso 3 - Recortes da fala do Ministro Paulo Guedes em palestra realizada na Fundação Getúlio Vargas em defesa da reforma administrativa

\begin{tabular}{|l|}
\hline \multicolumn{2}{|l|}{ Discurso de: Paulo Guedes } \\
\hline Veiculado: Jornal eletrônico G1.Globo \\
\hline Ano: 2020 \\
\hline Recorte do discurso: \\
\hline
\end{tabular}


O hospedeiro está morrendo, o cara virou um parasita, o dinheiro não chega no povo e ele quer aumento automático.

O recorte da fala do ministro Paulo Guedes, constante na Tabela 3, é parte de um discurso proferido por ele em uma palestra realizada na Fundação Getúlio Vargas, no início do ano de 2020, em defesa da proposta de reforma administrativa a ser apresentada pelo governo federal. Essa proposta de reforma administrativa prevê mudanças definitivas e expressivas nas relações de trabalho entre o funcionalismo público e o estado brasileiro. A ideia principal dessa proposta é reestruturar as carreiras do funcionalismo público, o que inclui um enxugamento das carreiras do poder executivo, além do estabelecimento de novas formas de vínculos empregatícios, remuneração, flexibilidade para demissão etc., enfim um panorama totalmente diverso do atual. Tal ação, entre outras que serão tomadas pelo governo federal, é vista por ele como uma forma de promover os ajustes necessários nas contas públicas, em razão da atual crise financeira do país, e a modernização da administração do estado brasileiro.

Nesse contexto observamos o Ministro Paulo Guedes desmoralizar o funcionalismo público, alvo principal da reforma administrativa, por meio de um discurso que o desqualifica e o identifica como "parasitas", aqueles que vivem às custas do Estado, permanecendo alheios às condições econômicas da sociedade brasileira, para com quem tem uma conduta desidiosa e negligente. Essa escolha lexical para definir o funcionário público, ao integrar o enunciado concreto, não se constitui apenas em simples unidade de língua, não representa apenas seu significado linguístico, pois seus sentidos e significações são construídos a partir das condições reais em que se dá essa enunciação e do posicionamento ideológico de quem a enuncia. No caso, as condições reais são cercadas por outras enunciações, igualmente pejorativas, que circulam ou já circularam na esfera da comunicação alcançadas pela fala do ministro, mostrando que elas dialogam entre si e que influenciam a atitude responsiva da sociedade a essa definição de funcionário público, enunciada pelo ministro.

Mais uma vez, observa-se o funcionário público se tornando a variável a ser discutida no universo de soluções propostas para a promoção dos ajustes fiscais e econômicos necessários a contenção da crise econômica e financeira atravessada pelo país. Fato que deixa explícita a desvalorização, por parte do governo, do seu capital humano e intelectual e a sua persistência em manter o mesmo discurso, já estabilizado e pejorativo, a respeito de seus funcionários. A manutenção desse discurso pejorativo, supostamente, está atrelada à necessidade de apoio da sociedade à implementação de medidas restritivas dirigidas ao funcionalismo público, alvo de críticas e de oposição por parte do governo e da sociedade brasileira.

\section{RECORTE DO ARTIGO DE OPINIÃO - DIA DO SERVIDOR PÚBLICO: UMA HOMENAGEM A QUEM FAZ FUNCIONAR O PAÍS} Tabela 4: Discurso 4 - Recorte do artigo de opinião, intitulado Dia do servidor
público: uma homenagem a quem faz funcionar o país

\begin{tabular}{|l|l|}
\hline \multicolumn{2}{|l|}{ Discurso de: Walmaro Paz } \\
\hline Veiculado: Site de notícias Brasil de Fato \\
\hline Ano: 2020 & Acesso: $10 / 11 / 2020$ \\
\hline
\end{tabular}


Neste dia 28 de outubro, comemora-se oficialmente o Dia do Servidor Público no Brasil. Atualmente, segundo dados do Ministério da Economia, a União possui 553 mil servidores concursados, 68 mil deles com idades acima de 60 anos, muito próximos da aposentadoria. São estas pessoas que realizam as políticas públicas no Brasil tornando-as políticas de Estado e não de governos. São os profissionais da saúde, os professores das universidades, os policiais federais. Enfim, as pessoas que fazem o país funcionar com segurança, saúde e educação. Além deles, temos os servidores municipais e estaduais que realizam as mesmas funções.

Considerados pelos liberais e conservadores como um peso para a sociedade, são eles que arrecadam impostos, ensinam nossos filhos, tratam de nossos problemas de saúde, orientam nossas aposentadorias, servindo com dignidade e competência, apesar de todas as críticas que sofrem. Até a Constituição de 1988, eram chamados de funcionários públicos e passaram a ser designados como servidores naquela ocasião.

A data de 28 de outubro não foi escolhida por acaso. Foi nela que o presidente Getúlio Vargas assinou o decreto $\mathrm{n}^{\mathrm{0}} 1713$, de 28 de outubro de 1939, que criou o Conselho Federal do Serviço Público Civil. Desde o Império essas pessoas que fazem funcionar as instituições lutavam pela regulamentação de sua profissão e pelo reconhecimento de seus méritos. Embora na sua origem fossem nomeados em função de interesses políticos. Desde 1939, eles passaram a iniciar suas carreiras por concurso público.

Em um artigo intitulado Dia do servidor público: uma homenagem a quem faz funcionar o país, publicado na coluna de opinião do site de notícias denominado Brasil de Fato, o jornalista Walmaro Paz enuncia entre algumas informações a respeito do funcionário público, sua opinião pessoal sobre esses trabalhadores. Publicado como uma homenagem aos funcionários públicos, pelo seu dia, o artigo aponta um pouco da trajetória e da sua importância para a sociedade. Percebe-se que ao contrário das enunciações que circulam nas diversas esferas da comunicação, a respeito do funcionário público, o jornalista fez escolhas linguísticas que contribuíram para valorizar e desmistificar a imagem depreciativa desses trabalhadores, apontando para uma realidade social construída a partir do trabalho do funcionário público. Esse trabalho é visto pelo jornalista como essencial ao atendimento das necessidades prioritárias da sociedade, cujo atendimento imediato e indispensável está sob a responsabilidade do estado. Assim, da sua posição de usuário do serviço público, o jornalista percebe o funcionário público não como um peso para a sociedade, mas como um gestor público de importância fundamental para assegurar o atendimento das necessidades e dos direitos da sociedade, evidenciando a relevância do seu trabalho e da sua contribuição à condução e ao funcionamento do estado brasileiro. Esse é um enunciado que promove um confronto entre a visão estereotipada do funcionário público, já estabilizada no meio social, e a visão positiva a seu respeito, evidenciada nas enunciações que destacam sua atuação a favor da sociedade, provocando dessa forma uma reflexão a respeito desses trabalhadores. Construindo um enunciado que traz em si o seu juízo de valor em relação a esses trabalhadores, o jornalista contribuiu, por meio de um movimento dialético, para a construção de novas significações e de novos conceitos ideológicos a respeito dos funcionários públicos. 


\section{CONSIDERAÇÕES GERAIS A RESPEITO DOS ENUNCIADOS}

Na maioria dos enunciados analisados nessa pesquisa, podemos observar um teor pejorativo que propicia o surgimento de estereótipos atribuídos ao funcionário público, cujas significações foram sendo construídas e fortalecidas durante o processo de interação social em que esses enunciados se materializaram de forma concreta.

Embora produzidos em épocas distintas, a maioria desses enunciados abrigavam um mesmo conceito, que pode ser definido como histórico e social, a respeito do funcionário público: funcionários que não trabalham, são ineficientes, improdutivos, caracterizados como um peso para o estado que os remunera de forma generosa.

O fato descrito acima reflete a afirmação de Bakhtin (1997), de que o enunciado presente está repleto de ecos e lembranças de enunciados passados que já circularam em um movimento dialético de interação verbal.

Diante disso, podemos observar que esse discurso pejorativo a respeito do funcionário público, que ecoou e se repetiu na maioria dos enunciados analisados, já está estabilizado na sociedade, onde ocupa uma posição bem definida, razão pela qual sempre emerge em novos enunciados, sendo considerados e avaliados quando da produção de novos discursos dirigidos a esses trabalhadores.

Com relação ao enunciado do jornalista Walmaro Paz, que ao contrário dos demais enunciados promove uma valorização do funcionário público, podemos considerá-lo, de acordo com a teoria bakhtiniana, uma resposta a enunciados anteriores aos quais ele discorda e refuta dentro da esfera comunicativa. Pois, se por um lado, por exemplo, a esfera governamental elegeu o funcionário público como causa dos problemas enfrentados pela administração pública, por outro lado, o jornalista, como membro da sociedade civil, o enxerga como a solução para o atendimento das necessidades sociais. Isso ocorre porque cada ator social ao se enunciar sobre o funcionário público, se enuncia de uma posição ideológica, construindo, portanto, enunciados que refletem seus posicionamentos e juízos de valor a respeito desses trabalhadores. O jornalista se enunciou da sua posição de usuário dos serviços prestados pelos funcionários públicos. A esfera governamental se enunciou da sua posição de patrão desses funcionários e a partir da sua visão neoliberal, segundo a qual o funcionário público representa um peso para o estado brasileiro e os serviços públicos, causas de grande endividamento do governo. São posicionamentos que interferem, por meio das relações dialógicas que instituem, na construção e na reprodução da imagem social do funcionário público, de forma negativa ou positiva, dependendo da intenção comunicativa de cada enunciador.

\section{CONSIDERAÇÕES FINAIS}

As observações acima nos mostram que os discursos dialogam entre si, e segundo Bakhtin, refletem e refratam a realidade vivida pelos grupos sociais, formando a consciência ideológica dos sujeitos na sociedade. 
Por essa razão, podemos dizer que os enunciados a respeito dos funcionários públicos, aqui apresentados, sejam eles pejorativos ou não, são de natureza ideológica, pois refletem as crenças e as significações a respeito do funcionário público, e contribuem para a formação da consciência ideológica da sociedade a seu respeito.

Essa consciência ideológica a respeito do funcionário público somente pôde ser construída a partir do processo de interação social, por meio das ações comunicativas. Essas ações comunicativas abrigavam em si signos que refletiam não apenas o seu significado linguístico, mas todo o juízo de valor de seus enunciadores. Esse juízo de valor deu o tom valorativo às enunciações, que em sua maioria ganharam um teor pejorativo, contribuindo assim para a estabilização das crenças e das significações negativas a respeito dos funcionários públicos, fortalecendo, consequentemente, sua imagem negativa no meio social.

Tal situação nos mostra que a ideologia é construída a partir do índice de juízo de valor da sociedade e que ambos, valoração e ideologia se materializam no enunciado por meio das interações sociais.

\section{REFERÊNCIAS}

BAKHTIN M. Estética da criação verbal. 2 ed. Fontes, 1997.

BAKHTIN M. Marxismo e filosofia da linguagem. 12 ed. Hucitec, 2006.

BERTI-SANTOS, S. S. Esferas de produção, circulação e atualização: do discurso literário ao discurso jornalístico. In: UYENO, E.Y.; PUZZO, M.B.; RENDA,V.L.B.S. (org.). Linguística aplicada, Linguística e Literatura: Interseções Profícuas. Campinas: Pontes, 2012. p. 171-201.

CAVALCANTI, Armando; CALDAS K. Maria Candelária. 1952. Disponível em: https://www.letras.com.br/armando-cavalcante/biografia. Acesso em 07/06/2020.

Acesso em: 08/06/2020.

CAMPANHA Acabar com os privilégios de quem trabalha pouco, ganha muito e se aposenta cedo. Essa é a verdade. Disponível em: https://twitter.com>planalto $>$ status. Acesso em: 16 Ago 2019.

CHIAVEnATO, Idalberto. Administração Geral e Pública. Teoria e mais de 500 questões com gabarito. 2. ed. Rio de Janeiro: Elsevier, 2009.

GIL, A. C. Métodos e Técnicas de Pesquisa Social. 6. ed. São Paulo: Atlas S. A., 2008. GODOY, A. S. Introdução à pesquisa qualitativa e suas possibilidades. In: Revista de Administração de Empresas, São Paulo, v. 35, p. 57-63, 1995.

GUEDES, Paulo. Palestra Fundação Getúlio Vargas. 2020. G1.Globo. Disponível em: https://g1.globo.com/economia/noticia/2020/02/07/paulo-guedes-compara-funcionariopublico-a-parasita-ao-defender-reforma-administrativa.ghtml. Acesso em: 08/06/2020. INSTITUTO DE PESQUISA ECONÔMICA APLICADA - IPEA. Nota Técnica: Três décadas de evolução do funcionalismo público no Brasil (1986 - 2017): Atlas do estado brasileiro. Brasília [s.d.]. Disponível em https://www.ipea.gov.br/atlasestado/download/154/tres-decadas-de-funcionalismobrasileiro-1986-2017. Acesso em: 10/11/2020.

MACHADO, I. Gêneros discursivos. In: Brait, B. (org.). Bakhtin conceitos-chave. São Paulo: Contexto, 2005. p. 151-166. 
PAZ, Walmaro. Dia do servidor Público: uma homenagem a quem faz funcionar o país.2020. Brasil de fato. Disponível em: https://www.brasildefators.com.br/2020/10/27/artigo-dia-do-servidor-publico-umahomenagem-a-quem-faz-funcionar-o-pais. Acesso em 10/11/2020.

Artigo recebido em: ago. de 2020.

Aprovado e revisado em: nov. de 2020.

Publicado em: dez. de 2020.

Para citar este texto:

TRIGO, Mára Rubia. O Funcionário Público e Sua Imagem Social. Entremeios [Revista de Estudos do Discurso, ISSN 2179-3514, on-line, www.entremeios.inf.br], Seção Estudos, Programa de Pós-Graduação em Ciências da Linguagem (PPGCL), Universidade do Vale do Sapucaí (UNIVÁS), Pouso Alegre (MG), vol. 22, p. 187-203, jul. - dez. 2020.

DOI: $\underline{\text { http://dx.doi.org/10.20337/ISSN2179-3514revistaENTREMEIOSvol22pagina187a203 }}$ 